\title{
Educação e Tecnologia: reflexões para uma compreensão crítica numa perspectiva dos estudos em Ciência, Tecnologia e Sociedade.
}

Marta Silva Lima Mondini mamondini@sme.curitiba.pr.gov.br 0000-0002-6741-6938 de Educação, Curitiba, Paraná, Brasil.

Nestor Cortez Saavedra Filho nestorsf@utfpr.edu.br

(000-0003-4139-8986

niversidade Tecnológica Federal do Paraná, Curitiba, Paraná, Brasil.

Luiz Ernesto Merkle merkle@utfpr.edu.br

Universidade Tecnológica Federal do Paraná, Curitiba, Paraná, Brasil.

\section{RESUMO}

Este artigo tem o objetivo de refletir sobre as relações entre educação, tecnologia e sociedade por meio de um estudo de caso que discute a implantação de políticas públicas educacionais para o uso das tecnologias nas escolas municipais de Curitiba, numa perspectiva dos estudos em Ciência, Tecnologia e Sociedade (CTS). Realizou-se um levantamento das principais iniciativas políticas por meio da estratégia de análise documental e, para ampliar as discussões, foram realizadas entrevistas com profissionais da educação, a fim de compreender como se deram as implantações no contexto escolar. As análises apontam para um entendimento determinista sobre tecnologia e educação nas políticas implantadas na Rede Municipal de Ensino (RME) de Curitiba, que se reflete em decisões políticas verticalizadas e numa formação de professores e professoras centrada no conhecimento instrumental.

PALAVRAS-CHAVE: Educação. Ciência. Tecnologia e Sociedade. Determinismo Tecnológico. Políticas Públicas Educacionais. Rede Municipal de Ensino de Curitiba. 


\section{INTRODUÇÃO}

De acordo com as Diretrizes Curriculares para a Educação Municipal de Curitiba (DCM, 2006), cabe à Secretaria Municipal da Educação (SME) incorporar as tecnologias na escola, entendendo o papel do Estado como "agente moderador das desigualdades" (CURITIBA, Prefeitura Municipal, 2006, p.69) e a tecnologia como "como instrumento fundamental de uma educação comprometida com o desenvolvimento da autonomia intelectual do estudante da escola pública e com sua inserção no mundo digital e midiático" (CURITIBA, Prefeitura Municipal, 2006, p.69), possibilitando assim, o exercício da cidadania. Para contemplar estes princípios, a Rede Municipal de Ensino (RME) de Curitiba iniciou a implantação de políticas públicas educacionais para o uso das tecnologias na escola na década de 1990, com o propósito de oferecer aos cidadãos e cidadãs condições de acesso aos conhecimentos e tecnologias produzidas pela sociedade e de aproximar os/as estudantes e docentes dos conhecimentos tecnológicos e da cultura digital (CURITIBA, Prefeitura Municipal, 2006).

No entanto, é preciso problematizar estas questões, refletindo se somente o acesso à tecnologia garantirá o exercício pleno da cidadania e o posicionamento crítico de educandos/das e docentes frente aos processos tecnológicos, sendo necessário avançar para o entendimento de um conceito de educação e tecnologia que possibilite a emancipação dos sujeitos.

Nesse sentido, este texto pretende discutir as relações entre educação, tecnologia e sociedade por meio de um estudo de caso sobre a implantação das políticas públicas educacionais na RME de Curitiba, refletindo sobre as concepções de educação e tecnologia implícitas nos objetivos dos projetos implantados e na visão dos/das profissionais da educação municipal e sobre a formação de professores/ras para o uso da tecnologia na escola. O estudo foi organizado inicialmente com uma análise documental, em que se realizou um levantamento das principais iniciativas da RME e num segundo momento foram analisadas entrevistas com profissionais que vivenciaram a implantação destes projetos na escola. O referencial teórico adotado toma como base as contribuições de Álvaro Vieira Pinto e Andrew Feenberg para discutir o conceito de tecnologia, e as relações com a educação tomam o discurso de Paulo Freire como espelho, numa perspectiva dos estudos em Ciência, Tecnologia e Sociedade (CTS).

\section{Reflexões sobre educação e tecnologia numa perspectiva crítica.}

Ao discutir sobre os desafios da educação frente às reestruturações que a tecnologia provoca à sociedade, Freire (2000) argumenta que, quanto mais a tecnologia vem tomando espaço e importância social, mais se necessita de uma rigorosa vigilância ética sobre ela. $\mathrm{O}$ autor conceitua a tecnologia como resultado e estímulo do desenvolvimento científico e tecnológico, como criação e expressão da criatividade humana, que não deve ser "divinizada" ou "diabolizadas", mas deve ser entendida "de forma criticamente curiosa" (FREIRE, 2002, p. 15). Nesse sentido, a educação com princípios democráticos e libertadores, deve promover o exercício de pensar criticamente sobre a tecnologia, "o exercício de pensar o tempo, de pensar a técnica, de pensar o conhecimento enquanto se conhece, de democrática à altura dos desafios do nosso tempo" (FREIRE, 2000, p. 46). 
Para Freire (1991) pensar nos desafios e contribuições da educação numa sociedade conceituada por Gadotti (1991) como "altamente tecnológica", é entender que se integrar e inserir-se no seu tempo é uma tarefa histórica dos sujeitos, compreendendo os contextos sociais e a história como possibilidade e não como algo determinado. Segundo o autor, "os avanços tecnológicos, por exemplo, não são em si mesmos, perfiladores de um amanhã dado como certo, espécie de alongamento aprimorado de uma certa expressão do hoje" (FREIRE, 2000, p. 42), ou seja, a história não é determinada ou preestabelecida pelos avanços da ciência e da tecnologia, ela é construída socialmente por homens e mulheres.

$\mathrm{O}$ pensamento que entende a tecnologia como fator determinante para o desenvolvimento, sendo "autogeradora e o único fundamento da sociedade moderna" (FEENBERG, 2009, p. 109), é conceituado por Feenberg (2009) como determinismo tecnológico. O determinismo tecnológico toma por base 0 pressuposto de que as tecnologias são independentes do contexto social em que estão inseridas e que possuem uma lógica funcional autônoma. Assim, "pode parecer que o destino da sociedade diante da tecnologia seja ficar dependente de uma dimensão não-social que age no meio social sem, entretanto, sofrer uma influência recíproca" (FEENBERG, 2009, p. 108). Neste pensamento descontextualizado, a tecnologia influencia a sociedade, mas não é influenciada por ela na base de seus processos.

Para o conceito determinista, as instituições sociais, como por exemplo a escola, precisam adequar-se às exigências da base tecnológica a fim de garantir o progresso, "os deterministas acreditam que a tecnologia não é controlada humanamente, mas que, pelo contrário, controla e molda a sociedade às exigências de eficiência e progresso" (FEENBERG, 2009, p. 46).

No entanto, na concepção de uma teoria não determinista ou teoria crítica proposta por Feenberg (2009), não são as instituições ou os atores sociais que devem se adequar às exigências da tecnologia, mas devem utilizar-se da tecnologia, realizando escolhas de técnicas viáveis para a resolução de um determinado problema, que se modifica de acordo com as necessidades sociais (FEENBERG, 2009). Na concepção desta teoria crítica, a tecnologia não é vista nem como determinante, nem como neutra: é conceituada como objeto social, que deveria estar sujeita a interpretações sociais e culturais. Assim, a tecnologia "não é só o controle racional da natureza: tanto seu desenvolvimento, quanto seu impacto são intrinsecamente sociais" (FEENBERG, 2009, p. 106).

Vieira Pinto (2005) discute que o termo "tecnologia" possui diversas interpretações e reúne quatro significados principais: a primeira interpretação define a tecnologia como "logos da técnica", entendida como a ciência, o estudo e a discussão da técnica, os modos de produzir algo. A segunda interpretação entende a tecnologia como simplesmente técnica, que para Vieira Pinto é o uso mais frequente e popular do conceito de tecnologia. A terceira definição concebe a tecnologia como o conjunto de técnicas que dispõe uma determinada sociedade. Nesta interpretação, a tecnologia é mencionada para medir os avanços das forças produtivas de uma sociedade em suas diversas fases históricas. A quarta interpretação discute a tecnologia como ideologia da técnica. A tecnologia, no seu sentido primordial, pode ser compreendida como a "ciência da técnica", porque a técnica, como ato produtivo, como produção da realidade objetiva, possibilita reflexões, conhecimentos e considerações teóricas: 
se a técnica configura um dado da realidade objetiva, um produto da percepção humana que retorna ao mundo em forma de ação, materializado em instrumentos e máquinas, e entregue à transmissão cultural, compreende-se tenha que obrigatoriamente de haver a ciência que o abrange e explore, dando em resultado um conjunto de formulações teóricas, recheadas de complexo e rico conteúdo epistemológico. Tal ciência deve ser chamada "tecnologia", conforma uso generalizado na composição das denominações científicas (VIEIRA PINTO, 2005, p. 221).

Para Vieira Pinto (2005), há um caráter inconsciente sobre a técnica que mostra a impotência do homem diante da ambição das máquinas, fator que extingue sua consciência. Assim, "não seria o homem de cada fase histórica quem adquiriria a técnica possível de conseguir, e sim a técnica inexoravelmente determinada a surgir nessa época que se apossaria do indivíduo e da sociedade" (VIEIRA PINTO, 2005, p. 157). Feenberg (2009) define este pensamento como determinista, Vieira Pinto (2005) como pensamento ingênuo e para este autor, é também ingênuo perguntar "aonde" a técnica poderá levar a humanidade, pois "a técnica inicia-se com o homem pela mesma razão que faz o homem iniciar-se com a técnica" (VIEIRA PINTO, 2005, p. 216).

Conforme Vieira Pinto (2005), a técnica não pode ser encarada como uma "entidade", "fenômeno" ou "força em si" determinando a realidade e as decisões da sociedade:

\begin{abstract}
No processo da produção do seu ser social, a técnica não determina o destino do homem, antes o homem determina o destino da técnica. E isso acontece não só pelo uso que fazem da técnica os grupos detentores do poder, beneficiando ou prejudicando a maioria da humanidade, quanto igualmente pelo rendimento que dela tiram, levando-a a florescer em novas criações do conhecimento e da capacidade da modificação do mundo (VIEIRA PINTO, 2005, p. 216).
\end{abstract}

A técnica pode ser "boa", segundo Vieira Pinto (2005), se auxiliar o homem nas descobertas de recursos de transformação da natureza que possibilitem uma convivência social mais fraterna e poderá ser "má" se for aplicada para a exploração de seres humanos. No entanto, "tal resultado não deve ser imputado ao puro emprego material da técnica, mas aos intuitos desumanos maliciosos a quem pode servir, quando manejada por uma consciência antissocial com propósitos de dominação" (VIEIRA PINTO, 2005, p. 217). Assim como discutido em Feenberg (2009), a técnica estará sempre dependente dos interesses da humanidade.

No exercício de compreensão sobre a tecnologia numa perspectiva crítica, a prática educativa é destacada por Freire (2000) como importante elemento de confrontação aos desafios que as inovações tecnológicas impõem, elemento de denúncia e anúncio da realidade, entendendo as possibilidades e limitações da educação. Conforme Freire (2000, p. 41) "se, de um lado, a educação não é a alavanca das transformações sociais, de outro, estas não se fazem sem ela".

Vieira Pinto (2010) acrescenta que a educação é antes de qualquer coisa prática social e que "somente uma educação não alienada pode servir aos objetivos da sociedade em luta pelo desenvolvimento e pela transformação da vida do homem" (VIEIRA PINTO, 2010, p. 59). A forma crítica de entender o processo educativo é compreender que "a educação se concebe como um diálogo entre dois homens, na verdade entre dois educadores. Daí que a educação seja uma forma 
particular de responsabilidade da ação entre os homens" (VIEIRA PINTO, 2010, p.38).

Se a opção é por uma educação crítica, libertadora e dialógica defendida por Freire, sabe-se que a educação precisa ser mais que treinamento, "na visão pragmático-tecnicista, contida em discursos reacionariamente pós-modernos, o que vale é a transferência de saberes técnicos, instrumentais, com que se assegure boa produtividade ao processo produtivo" (FREIRE, 2000, p. 43). Em uma educação com princípios democráticos, não se pode dicotomizar a formação técnicocientífica dos educandos do exercício de pensar criticamente sobre a ciência e a tecnologia.

\footnotetext{
Me parece demasiado óbvio que a educação de que precisamos, capaz de formar pessoas críticas, [...] curiosas, indagadoras, não pode ser a que exercita a memorização mecânica dos educandos. A que "treina", em ligar de formar. Não pode ser a que "deposita" conteúdos na cabeça "vazia" dos educandos, mas a que, pelo contrário, os desafia a pensar certo (FREIRE, 2000, p. 46)
}

Assim, Freire defende uma pedagogia crítico-dialógica, em que ocorra uma construção crítica e coletiva do conhecimento por meio do diálogo, "articulando o saber popular e o saber crítico, científico, mediados pela experiência no mundo" (FREIRE, 1991, p. 83). A pedagogia contrária à dialógica é a concepção bancária, em que a educação é entendida como o "ato de depositar, de transferir, de transmitir valores e conhecimentos" (FREIRE, 1987, p. 34) aos que "nada sabem", refletindo os referenciais de uma sociedade opressora que estimula e mantém as contradições entre os sujeitos.

A formação docente implica na promoção da curiosidade ingênua à curiosidade epistemológica, alicerçadas no exercício da criticidade, entendendo e recriando a realidade educacional em que o docente atua (FREIRE, 1996). Assim, como Freire, Vieira Pinto (2010) acredita que a formação de professoras e professoras não deve estar desligada da sociedade e, portanto, da tecnologia, enquanto componente tecnológico na formação de professores e professoras.

Para Vieira Pinto (2005), é a sociedade que educa o educador, as aprendizagens originam-se sempre da sociedade, mas, geralmente, há um descompasso entre a consciência do educador (sua prática pedagógica e formação profissional) e as exigências impostas a ele numa sociedade onde o progresso tecnológico é relevante. Para que isso possa ser superado, Vieira Pinto (2010) assegura que a formação precisa preparar o educador para serem forças atuantes no seu contexto educacional e no desenvolvimento da sociedade.

\section{Estudo de caso: a implantação de políticas públicas educacionais para o uso das tecnologias nas escolas da RME de Curitiba.}

Buscando compreender e discutir as relações entre educação e tecnologia numa perspectiva crítica, passamos a analisar, como estudo de caso, a implantação de políticas públicas educacionais para o uso das tecnologias na escola, especificamente no contexto da Rede Municipal de Ensino de Curitiba. A metodologia utilizada foi a análise documental, a fim de investigar as principais 
período, além de entrevistas com profissionais da educação que vivenciaram as iniciativas políticas na escola, num total de 35 profissionais (professores e professoras, diretores e diretoras e pedagogas).

A pesquisa documental revela que os primeiros computadores adquiridos pela Secretaria Municipal da Educação (SME) chegaram às escolas no ano de 1992, inicialmente para informatizar o sistema escolar. De acordo com Costa (2010), este foi um passo importante na medida em que promoveu o contato dos/das profissionais com a tecnologia, a qual "precisava ser colocada ao alcance das novas gerações" (COSTA, 2010, p. 50). A partir desta iniciativa, outras políticas públicas educacionais promoveram o uso das tecnologias nas escolas de Curitiba, as quais, segundo as Diretrizes Curriculares para a Educação Municipal de Curitiba (2006) tinham o objetivo de promover o acesso destas ferramentas aos/ás estudantes e comunidade em geral.

Relações entre educação e tecnologia: principais iniciativas de implantação da tecnologia nas escolas da RME de Curitiba

Na década de 1990, a principal iniciativa política para a implantação da tecnologia na escola foi o projeto Digitando o Futuro em 1997, que procurou implantar os laboratórios de informática nas escolas por meio do processo de descentralização de recursos na contratação de empresas locais de informática que seriam responsáveis pela instalação e manutenção das máquinas e capacitação de professores/ras (COSTA, 2010).

Na década de 2000, a ideia foi revisitar os objetivos do projeto Digitando o Futuro ampliando as ações para além da compra de computadores e definição de softwares educativos. A capacitação dos/das profissionais da educação municipal para a realização de práticas com as tecnologias foi assumida pela equipe da SME, com a criação da Gerência de Tecnologias em 2003, buscando compreender a realidade do contexto escolar da Rede. Também se destacam a oferta de cursos de formação com o objetivo de oportunizar ao/á profissional o trabalho com diferentes tecnologias e integrar as ferramentas tecnológicas em sua prática pedagógica: Robótica, Linguagem Logo, Programa Lego nas escolas, Jornal Eletrônico Extra-Extra e Internet aos conteúdos curriculares (CURITIBA, Prefeitura Municipal, 2003).

No período de 2010 e 2012, observa-se que o objetivo das principais políticas era ampliar as possibilidades de trabalho de professores e professoras adquirindo novos recursos tecnológicos. Assim, a SME adquiriu 20.000 netbooks educacionais, a partir do Programa "Um Computador por Aluno", o PROUCA do Governo Federal, que passariam a ser utilizados pelas crianças do segmento da educação infantil ao 5o ano, de aproximadamente 180 escolas do município (CURITIBA, Prefeitura Municipal, 2012).

Na mudança de gestão municipal, em 2013, este projeto foi reconfigurado e a proposição deste período foi o projeto Conexão Educacional, que visava inserir, manter e acompanhar as tecnologias nas unidades educacionais (CURITIBA, Prefeitura Municipal, 2013).

Passando para a análise das entrevistas, ao ouvirmos o depoimento dos/das profissionais da educação municipal de Curitiba, observamos que os investimentos e projetos de implantação propostas pela SME são relevantes para o acesso de 
educandos/das e profissionais às tecnologias, como vemos exemplificado no depoimento da professora 4 da escola 2:

Participei desde o início (dos projetos de implantação da tecnologia na escola). A prefeitura oferecia cursos de várias linguagens: o Micromundos, a questão da linguagem Logo, os Legos, o Extra-Extra [...]. Eu participei de vários cursos, vários projetos da RME e que trouxeram muito conhecimento (Professora 4 - Escola 2).

No entanto, algumas profissionais apontam as descontinuidades das propostas de implantação e a falta de participação dos/das profissionais nas decisões políticas que interferem no trabalho com a tecnologia na escola como elementos que dificultam o trabalho pedagógico:

A coisa ruim da prefeitura é isso, tem o projeto, se trabalha bem, há todo um crescimento com o projeto, aí termina, e vem o próximo projeto. Então, eu acho que essas quebras, não são interessantes. E aí você vê bem a questão política [...]. É bem fragmentado, não tem assim um crescimento. Pelo menos eu, que tenho acompanhado toda essa parte das tecnologias, vejo que são (propostas) estanques (Professora 21 - Escola 12).

Eu acredito que (uma sugestão seria) ter uma conversa com a escola, porque, às vezes, vêm projetos que pouco se traduzem na necessidade da escola, ou pouco impacto vai ter sobre a aprendizagem. Ouvir mais as escolas é fundamental, porque nós temos muita coisa para contribuir (Diretora 3 Escola 6).

Como discutido por Freire (1991), é tarefa histórica dos sujeitos compreender e integrar-se aos desafios e manifestações do seu tempo, entendendo a história e a educação, que é profundamente histórica, como possibilidade. Assim, a implantação de iniciativas políticas para o trabalho com a tecnologia nas escolas da RME de Curitiba é importante na medida em que provocam nos/nas profissionais e educandos/das a compreensão das diversas manifestações sociais e culturais, como a tecnologia.

No entanto, as descontinuidades das propostas políticas de implantação e a falta de envolvimento e participação dos/das profissionais nas decisões destacadas pelas entrevistadas não colaboram para um entendimento crítico sobre a tecnologia e para a construção de uma educação com princípios críticos e democráticos, defendido por Freire (1997), que sugere o diálogo como elemento de superação da contradição entre os sujeitos. Uma educação problematizadora, que tem por base o diálogo, "rompe com os esquemas verticais característicos da educação bancária" (FREIRE, 1987), e, portanto, exige um diálogo entre as iniciativas do governo municipal e interesses e necessidades dos/das profissionais para a promoção de uma educação crítica, problematizadora e que emancipe os sujeitos da educação.

\section{Análises conceituais sobre a tecnologia na RME de Curitiba.}

De acordo com as Diretrizes Curriculares para a Educação Municipal de Curitiba (2006), a tecnologia é entendida como um fator importante na transformação de um modelo de sociedade que privilegia a poucos e somente o acesso permanente dos cidadãos e cidadãs ao conhecimento e as tecnologias 
produzidas pela sociedade promoverá esta transformação. De acordo com Costa (2010), no Projeto Digitando o Futuro, que inseriu os laboratórios de informática nas escolas de Curitiba na década de 1990, o computador, por exemplo, era entendido como instrumento de transformação, e que traria algo novo para a educação.

A tecnologia também é entendida nos documentos da SME, como um instrumento fundamental para uma educação comprometida com o desenvolvimento intelectual de seus/suas estudantes e "com sua inserção no mundo digital e midiático, o que lhe garantirá condições cognitivas, intelectuais e emocionais de exercer plena e conscientemente sua cidadania" (CURITIBA, Prefeitura Municipal, 2006, p. 69).

Refletindo sobre o conceito de tecnologia contido nos documentos da RME de Curitiba, vemos que este conceito se aproxima ao discutido por Feenberg (2009), que apresenta um conceito determinista de tecnologia, entendendo-a como autogeradora do progresso e fundamento da sociedade moderna, que influencia a sociedade, mas não é influenciada por ela. Para Feenberg (2009), numa perspectiva crítica, a tecnologia não pode ser conceituada como condição, fator determinante ou como instrumento necessário para a transformação da sociedade, deve ser encarada como objeto social, em que tanto seu desenvolvimento quanto seu impacto serão de aspectos sociais. Assim entendida, a tecnologia pode estar sujeita a inquietações, problematizações ou interpretações sociais e culturais.

$\mathrm{Na}$ análise das entrevistas, o depoimento dos/das profissionais nos revela que a visão de parte dos/das docentes reflete a concepção determinista que os documentos oficiais da RME trazem sobre tecnologia, entendendo-a como fator determinante no contexto da educação, argumentando que não há como distanciar-se do que a tecnologia propõe, pois as crianças já nascem num contexto tecnológico e não como "escapar" dessa questão:

\footnotetext{
O que falta [...] é ver que não tem escapatória, é o futuro, os professores vão conseguir que os alunos aprendam muito mais com as tecnologias (Professora 17 - Escola 9).
}

Sempre digo no início da aula que eu vou ensinar ferramentas para a vida deles, eles vão aprender a usar a tecnologia para a vida deles [...]. Porque as crianças já nascem hoje com a tecnologia (Professora 1 - Escola 1)

No entanto, outra parcela dos/das profissionais entende a tecnologia como um adendo, um acréscimo à educação, como uma ferramenta, mas que, sozinha, não será elemento transformador da realidade educacional:

\footnotetext{
Não houve uma mudança no procedimento escolar, na vida escolar, pedagogicamente não houve uma mudança (com a tecnologia na escola), mas houve um acréscimo. Então, eu vejo assim, que as crianças se estimulam a estudar e colaboram com o professor quando (a aula) é ligada a tecnologia. Nesse aspecto, acho que é um grande adendo à educação o recurso da tecnologia (Diretora 1 - Escola 2).
}

Eu acho que é mais uma ferramenta, não é a solução para a educação, mas eu acho que é mais uma ferramenta para nós (Professora 3 - Escola 2). 
Outras docentes avaliam a necessidade de uma compreensão reflexiva da tecnologia, reconhecem a facilidade e dos/das estudantes ao utilizar os recursos tecnológicos, mas que ainda lhes falta a criticidade na compreensão sobre a tecnologia e sua utilização, sendo necessário a intervenção do/da professor/ra como vemos nos depoimentos das professoras 9 e 4:

Eu vejo, às vezes, a imaturidade deles, o aluno também precisa estar focado, centrado, $[\ldots]$ nós queremos usar tantos recursos tecnológicos que nós não percebemos que os alunos, muitas vezes, não estão preparados (Professora $9-$ Escola 4)

Eu acho que a tecnologia não pode ser só a questão virtual, nós não podemos esquecer que somos pessoas [...]. O ser humano vem em primeiro lugar e a tecnologia é uma consequência, porque foi criada pelo homem. Não foi a tecnologia que criou o homem, foi o homem que criou a tecnologia, teve inteligência para isso. Tem que ter essa relação com o humano, até para aproveitar melhor a tecnologia e aproveitá-la de forma adequada (Professora 4 - Escola 2).

Ao se referirem à tecnologia como ferramenta e acréscimo ao trabalho pedagógico, o conceito de tecnologia entendido por parte destas docentes, se assemelha ao segundo conceito discutido por Vieira Pinto (2005): a tecnologia como simplesmente técnica, que para o autor é o conceito mais frequente e popular sobre tecnologia, um conceito que pode definir a tecnologia, mas ainda numa visão "habitual, coloquial e sem rigor" (VIEIRA PINTO, 2005, p. 219).

Seria interessante discutir também com os/as profissionais o conceito de tecnologia entendendo-a como ideologia da técnica, refletindo sobre as percepções humanas, sobre a ação que transforma os objetos materializados em máquinas, as transmissões culturais nestes processos, e as formulações teóricas desta ciência "recheadas de complexo e rico conteúdo epistemológico" (VIEIRA PINTO, 2005, p. 221). Nesse processo, o exercício de pensar criticamente sobre a tecnologia deve ser proporcionado pela educação que se compromete com a formação crítica de seus/suas estudantes e docentes, como discute Freire (2000) e como apontam o depoimento das professoras 4 e 9.

\section{Formação de professores/ras para o uso das tecnologias na escola.}

De acordo com as DCM (2006), é dever da Secretaria Municipal da Educação (SME) a implantação das tecnologias na escola e a formação continuada dos/das profissionais:

Cabe à Secretaria Municipal da Educação o papel de implementar e incorporar as tecnologias da informação e da comunicação aos projetos pedagógicos das escolas da RME, através da qualificação continuada de seus profissionais (CURITIBA, Prefeitura Municipal, 2006, p. 69).

O processo de formação de professores/ras para o uso das tecnologias nas escolas da RME de Curitiba foi constituindo-se na medida em que os projetos foram sendo implantados, inicialmente sendo ofertados cursos pelas empresas responsáveis pela implantação dos laboratórios de informática e, posteriormente, com a criação da Gerência de Tecnologias, esta formação foi assumida pela equipe 
da SME com o objetivo de "assessorar e capacitar os profissionais da educação municipal para a realização de práticas nas unidades de ensino que utilizassem tecnologias digitais" (CURITIBA, Prefeitura Municipal, 2006, p. 66).

No recente projeto de formação de professores/ras, o Edutecnologia, lançado em 2013, a formação dos/das profissionais da educação é entendida como um desafio constante e a formação objetivada por este projeto se propõe ajudar o/a profissional a aperfeiçoar o uso pessoal e social da tecnologia para que isso se reflita em sua prática pedagógica. A troca de experiências e compartilhamento de materiais também são princípios deste programa de formação continuada.

Na análise das entrevistas, os depoimentos dos/das profissionais indicam que os cursos de formação sempre agregam algum conhecimento e que os/as profissionais se organizam para realizá-los, como vemos exemplificado no depoimento da professora 22, mas sentem dificuldade pela limitação de vagas, cursos ofertados no período noturno e fora do horário da permanência, como indica a professora 11:

\footnotetext{
Os cursos agregam. Eu acho que o professor tem que querer buscar novas ferramentas, novas tecnologias para motivar os nossos educandos (Professora 22 - escola 15).
}

Tentei me inscrever em um e não consegui. Era um curso de Ciência e Tecnologia para a rede inteira, sendo só duas vagas para este núcleo, então não teve como (Professora 11 - Escola 5).

Os/As profissionais argumentam que muitos cursos são focados no saber instrumental, fazendo poucas reflexões sobre as relações entre a tecnologia e o contexto educacional. Para parte dos/das profissionais entrevistados/das, a descontinuidade das iniciativas políticas interfere também na formação de professores/ras, que muitas vezes são estanques ou fragmentadas:

Tem curso de capacitação, mas não da forma como gostaríamos de trabalhar com a prática da escola, é diferente a visão deles (SME) e a prática escolar, a realidade da escola (Diretor 5- Escola 14).

Nós temos muitos cursos de formação, mas é assim, é esse programa, nós (a prefeitura) oferecemos esta formação. Eu, desde 2002, estou fazendo um curso. E é ofertado muitos cursos. A única questão é que tem o programa, você faz o curso, você prepara e aí a pouco "morre" este programa. A questão é que eles são estanques, são blocos (Professora 21 - Escola 12)

Uma concepção pragmática-tecnicista de educação considera que a simples transferência dos saberes técnicos aos/ás docentes assegurará a produtividade do trabalho, porém Freire (2000) discute que a formação técnica-científica de educandos/das, professores e professoras não pode acontecer separada da formação crítica. Assim, o objetivo de uma formação crítica de professoras e professores é colaborar para que sejam forças atuantes em seu contexto educacional, como discutido em Vieira Pinto (2010), contribuindo para a mudança da condição humana dos sujeitos da educação.

Como indicado pelo referencial teórico e pelos depoimentos das profissionais da RME de Curitiba, a formação continuada dos professores e professoras deve superar a visão instrumental e fragmentada da educação, pois, como discutimos em Freire (1987), uma educação que concebe os sujeitos da educação como seres 
passivos e que apenas devem receber os conteúdos da formação reflete-se numa concepção de educação bancária. Para a educação libertadora e problematizadora, os sujeitos da educação são considerados conscientes de seu papel e o diálogo se faz necessário.

\section{Considerações finais}

O objetivo destas reflexões foi de compreender as relações entre educação, tecnologia e sociedade por meio do estudo de caso nas escolas da Rede Municipal de Ensino de Curitiba numa perspectiva dos estudos de Ciência, Tecnologia e Sociedade.

A análise documental mostra que existem investimentos em políticas e projetos para a implantação de tecnologias nas escolas da Rede Municipal de Ensino de Curitiba. Por outro lado, na análise das entrevistas com os/as profissionais, observa-se que a falta de continuidade das políticas educacionais e as decisões políticas verticalizadas tornaram as iniciativas pouco efetivas ao contribuir para a formação crítica dos/das estudantes. Em relação a formação de professores e professoras para o uso das tecnologias na escola, observa-se que estão centradas no saber instrumental não contemplando um conhecimento mais aprofundado sobre tecnologia, dialogando com as necessidades da escola, docentes e educandos/das.

As análises do estudo de caso da implantação das tecnologias na RME de Curitiba indicam uma visão determinista de tecnologia e educação contida nas decisões políticas, na qual, segundo Feenberg, a tecnologia é entendida como determinante e autogeradora do desenvolvimento. Faz-se necessária uma relação dialógica entre governos e escolas, no intuito de viabilizar processos de ensino e aprendizagem que sejam, de fato, cidadãos. A discussão crítica sobre educação e tecnologia é importante para refletir que somente o acesso a estes processos não garantirá a emancipação dos sujeitos como preveem as políticas, mas um trabalho pedagógico que possibilite o diálogo, a criticidade, a colaboração e a problematização da exploração desta tecnologia.

A formação continuada para o uso da tecnologia na escola dos/das profissionais da educação precisa considerá-los como sujeitos de sua aprendizagem e que, por meio de uma relação dialógica, os/as tornará forças atuantes na sociedade, princípios de uma formação crítica defendida por Freire e Vieira Pinto. O/A professor/ra crítico/ca e emancipado/da, consciente de seu papel na sociedade e com autonomia de trabalho, decidirá qual tecnologia contribuirá para o processo de ensino e aprendizagem de seus/suas educandos/das, quando e como será explorada. 


\title{
Education and Technology: reflections for a critical understanding from a perspective of studies in Science, Technology and Society.
}

\begin{abstract}
This article aims to reflect on the relationship between education, technology and society through a case study that discusses the implementation of educational public policies for the use of technologies in the municipal schools of Curitiba, from a perspective of studies in Science, Technology And Society (STS). A survey of the main political initiatives was carried out through the document analysis strategy and, in order to broaden the discussions, interviews were carried out with education professionals in order to understand how they were implemented in the school context. The analyzes point to a deterministic understanding of technology and education in the policies implemented in Curitiba's Municipal Schools, which is reflected in vertical political decisions and in the training of teachers focused on instrumental knowledge.
\end{abstract}

KEYWORDS: Education. Science, Technology and Society. Technological Determinism. Public Educational Policies. Municipal Schools of Curitiba. 


\section{REFERÊNCIAS}

COSTA, Vidal. Boletim Casa Romário Martins. Memória da Rede Municipal de Ensino de Curitiba- 1983-1998. Fundação Cultural de Curitiba, v.33, № 143, 2010.

CURITIBA. Prefeitura Municipal. Secretaria Municipal da Educação de Curitiba. DVD Programa TV Professor. Histórico das novas tecnologias na metodologia de ensino. Curitiba, 2003.

Prefeitura Municipal. Secretaria Municipal da Educação de Curitiba. Diretrizes Curriculares para a Educação Municipal de Curitiba. Volume 1 Princípios e Fundamentos. Curitiba, 2006.

Prefeitura Municipal. Secretaria Municipal da Educação de Curitiba. Programa Conexão Escola - Orientações Gerais. Curitiba, 2012.

Prefeitura Municipal. Secretaria Municipal da Educação de Curitiba. Programa Conexão Educacional, Curitiba, 2013.

FEENBERG, Andrew. Racionalização democrática, poder e tecnologia. Brasília: Observatório do Movimento pela Tecnologia Social na América Latina/Centro de Desenvolvimento Sustentável - CDS. Ciclo de Conferências Andrew Feenberg. Neder, Ricardo T. (org.), 2009.

FREIRE, Paulo. A máquina está a serviço de quem? Revista Armação em Bits, 1984.

Pedagogia do oprimido. Rio de Janeiro: Paz e Terra, 1987.

. A Educação na Cidade. São Paulo: Cortez, 1991.

Pedagogia da autonomia. Rio de janeiro: Paz e Terra, 1996.

. Pedagogia da Indignação - cartas pedagógicas e outros escritos. São Paulo: Editora Unesp, 2000.

VIEIRA PINTO, Álvaro. O Conceito de tecnologia - Volume 1. Rio de Janeiro: 
Recebido: 06 mai. 2016

Aprovado: 12 dez. 2016.

DOI: $10.3895 /$ rbect.v9n3.4047

Como citar:

MONDINI, M. S. L.; FILHO, N. C. S.; FLORCZAK, M. A.; MERKLE, L. E. Educação e Tecnologia: reflexões para uma compreensão crítica numa perspectiva dos estudos em Ciência, Tecnologia e Sociedade. Revista Brasileira de Ensino de Ciência e Tecnologia, v. 9, n. 3, 2016. Disponível em:

$<$ https://periodicos.utfpr.edu.br/rbect/article/view/4509>. Acesso em: xxx.

Correspondência:

Nestor Cortez Saavedra Filho

UTFPR, Campus Curitiba, Departamento Acadêmico de Física. Av. Sete de Setembro, 3165, Rebouças, Curitiba, PR. CEP: 80230-901

Direito autoral: Este artigo está licenciado sob os termos da Licença Creative Commons-Atribuição 4.0 Internacional. 